\title{
LINHA DO TEMPO DAS POLÍTICAS DE DESIGN: DAS GRANDES EXPOSIÇÕES ÀS POLÍTICAS INTERNACIONAIS INTEGRADAS
}

\author{
Daniel Dutra Gomes \\ Universidade Federal de Pernambuco \\ Studio Daniel Dutra \\ contato@danieldutra.com.br \\ Kátia Medeiros de Araújo \\ Universidade Federal de Pernambuco \\ katia_araujo@hotmail.com.br
}

Resumo: Desde o final do Século XVIII, o design é reconhecido por governos como estratégia de desenvolvimento. A entrega de programas e políticas de design ao redor do globo é distinta e se relaciona com o seu contexto político, econômico e cultural. Este artigo apresenta uma revisão histórica da evolução das políticas de design com o objetivo de auxiliar pesquisadores, designers e policy-makers a compreender como as políticas e programas de design surgiram e quais foram suas consequências sobre as economias nacionais. Este estudo propõe uma linha do tempo das políticas de design organizada em seis grandes fases, a partir de um levantamento de marcos históricos entre os Séculos XVIII e XXI, período das Grandes Exposições e feiras comerciais às atuais políticas internacionais integradas.

Palavras-chave: políticas de design, revisão histórica, promoção do design, suporte de design, ensino do design.

Abstract: Since the late 18th Century, design has been recognized by governments as a development strategy. The delivery of design policies are distinct and relates with their political, economical and cultural contexts. This paper presents a historical review of the evolution of design policies, in order to enable researchers, designers and policy-makers to understand how design programs and design policies emerged and what were its consequences on national economies. This study proposes a timeline of design policies structured on six periods, from a review of historical highlights between the 18th and 21st Century, period of the Great Exhibitions and tradeshows to current integrated international policies.

Keywords: design policy, historical review, design promotion, design support, design education. 


\section{INTRODUÇÃO}

Este artigo é fruto de reflexões em atividades de fundamentação teórica e de revisão bibliográfica que ocorreram na execução do projeto de pesquisa 'Diagnóstico do Design na Cidade de Vitória: Estratégias para uma Política Local', no Programa de Pós-Graduação em Design na Universidade Federal de Pernambuco.

Durante o estudo, foram investigados programas e políticas de design elaborados por países ao redor do globo a partir do final do Século XVIII e suas relações com seus contextos históricos.

\section{LINHA DO TEMPO DAS POLÍTICAS DE DESIGN}

Historicamente, a intervenção do governo no âmbito do design tem influenciado o desenvolvimento do design, da criatividade e da inovação, tanto em aspectos positivos quanto negativos. Neste trabalho, propõe-se uma divisão da história das políticas de design em seis grandes fases esquematizada na Figura 1.

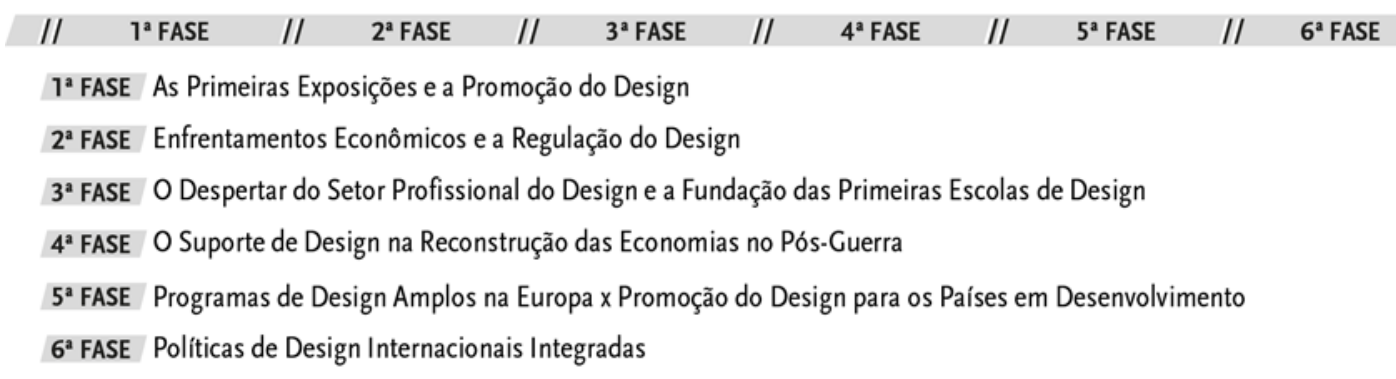

Figura 1 - Linha do tempo da Política de Design.

Fonte: Elaborado pelo autor.

É importante comentar que as políticas de design são entregues ao redor do globo por programas distintos em termos de estratégias, tempo e força política. Além disso, em sua maioria, combinam diferentes ações com capilaridades diferentes nas regiões internas dos países. A intenção do autor com esta marcação não é afirmar a existência de padrões estruturais cristalizados e rígidos, mas facilitar o entendimento do leitor sobre a gênese das políticas e programas de design ao longo do tempo e como estes se relacionam com o contexto político, econômico e cultural. As seis fases apresentadas anteriormente na Figura 1 serão detalhadas nos tópicos seguintes.

\subsection{Primeira Fase - As Primeiras Exposições e a Promoção do Design}

A origem das políticas de design é datada por alguns autores (RAULIK-MURPHY, 2010; PATROCíNIO, 2013) no final do Século XVIII e no início do Século XIX, período histórico em que houve o surgimento das primeiras feiras comerciais e industriais na Europa, cujo objetivo era promover o design.

É possível citar a Exposição da Indústria de Genebra, na Suíça em 1789, considerada como a primeira Feira de Comércio e Produto da Europa. Ainda no Século XVIII, houveram exposições em Hamburgo (Alemanha, 1790) e em Praga (República Tcheca, 1791) (SAYER, 2004).

Outro marco importante foi a Exposição da Indústria Francesa realizada em 1798, cujos produtos expostos foram agraciados com prêmios de reconhecimento público. Chandler (1990) argumenta que a exposição da França iniciou uma carreira de 
progresso tecnológico aplicado a melhorias na qualidade de vida, sendo um importante marco para a civilização ocidental.

A exposição mostrou-se como uma estratégia tão benéfica para a promoção da indústria e, consequentemente, do design francês que o evento foi repetido, aumentando de tamanho a cada vez, em 1839, 1844 e 1849 (RAULIK-MURPHY, 2010).

Nesse mesmo período, a iniciativa francesa inspirou exposições por toda a Europa: Berna, (Suíça, 1845); Madrid (Espanha, 1845); Bruxelas (Bélgica, 1847); Bordéus (França, 1847); São Petersburgo (Rússia, 1848); e Lisboa (Portugal, 1849) (RAULIK-MURPHY, 2010).

No âmbito internacional, a Grandes Exposição dos Trabalhos da Indústria de Todas as Nações, realizada em 1851, Século XIX, na cidade de Londres é considerada o grande marco para as ações de promoção do design (HUGHES, 2010).

A Exposição de Londres foi financiada pela revolução do tripé "carvão-vaporestradas" e consistiu em uma estratégia da burguesia inglesa para ampliar seus negócios. A feira estava acessível tanto aos nobres quanto ao proletariado. Dessa forma, a burguesia esperava alcançar também o mercado local, aumentando as vendas pelos contatos entre produtores e consumidores (LAKE-HAMMOND; WAITE, 2010).

Segundo uma Declaração do Council of the UK Society of Arts (Conselho da Sociedade Artística do Reino Unido), as feiras comerciais e industriais acirraram a concorrência entre as indústrias europeias, estimulando os fabricantes a buscar novas habilidades industriais, manter os melhores profissionais e estabelecer excelência nas escolhas de materiais, em termos de acabamento e durabilidade (HOBHOUSE, 2004).

Até o presente momento histórico narrado, o desenvolvimento de políticas e programas de design foi marcado pela promoção do design e sua exploração econômica como valor de diferenciação no mercado. As feiras e exposições, estratégias dessa primeira fase histórica da política de design, impulsionaram o crescimento econômico das economias dos países da Europa e iniciaram a formação de uma cultura de design no continente. Na Figura 2, apresentada a seguir, estão indicados os principais marcos históricos desta primeira fase.

\begin{tabular}{|c|c|c|c|c|}
\hline $\begin{array}{l}\text { EXPOSIÇÃO } \\
\text { DA INDÜSTRIA } \\
\text { DE GENEBRA } \\
\text { Suiça, } 1789 \\
\text { promoção do design }\end{array}$ & \begin{tabular}{|l} 
FEIRAS \\
COMERCIAIS \\
Alemanha, 1790 \\
República Tcheca, 1791 \\
promoção do design
\end{tabular} & \begin{tabular}{|l} 
EXPOSIÇÕES \\
DA INDÚSTRIA \\
FRANCESA \\
França, 1798 \\
promoção do design
\end{tabular} & \begin{tabular}{|l} 
EXPOSIÇÕES \\
DA INDÜSTRIA \\
Espanha, 1845 \\
Bélgica, 1847 \\
Rússia, 1848 \\
Portugal, 1849 \\
promocão do design
\end{tabular} & $\begin{array}{l}\text { GRANDES EXPOSIÇÃO } \\
\text { DOS TRABALHOS DA } \\
\text { INDÚSTRIA DE TODAS } \\
\text { AS NAÇŌES } \\
\text { Inglaterra, } 1851 \\
\text { promoção do design }\end{array}$ \\
\hline
\end{tabular}

Figura 2 - Marcos históricos da 1a fase da linha do tempo das políticas de design. Fonte: Elaborado pelo autor.

\subsection{Segunda Fase - Enfrentamentos Econômicos e a Regulação do Design}

Com a Revolução Industrial, os enfrentamentos entre as empresas quanto a utilização do design foi intensificado. A expansão do comércio e da pirataria fizeram com que no final do Século XIX os governos em todo o mundo intervissem com políticas na tentativa de organizar o sistema econômico e ajustar o mercado.

Em 1883, foi realizada a União Internacional para a Proteção da Propriedade Industrial ou Convenção de Paris (CUP). A conferência reuniu 14 países, incluindo o 
Brasil, e elaborou o primeiro tratado internacional sobre propriedade industrial (JUNGMANN, 2010).

Este acordo firmou duas regras para regulamentação da concessão de patentes: 1) a concessão para não residentes; 2 ) a territorialidade da patente, isto é, a validade apenas no país onde foi concedida (JUNGMANN, 2010). A CUP foi um marco internacional importante no surgimento das políticas de design, particularmente na organização dos programas nacionais de regulação do design.

Este acontecimento pode ser visualizado esquematicamente na Figura 3.

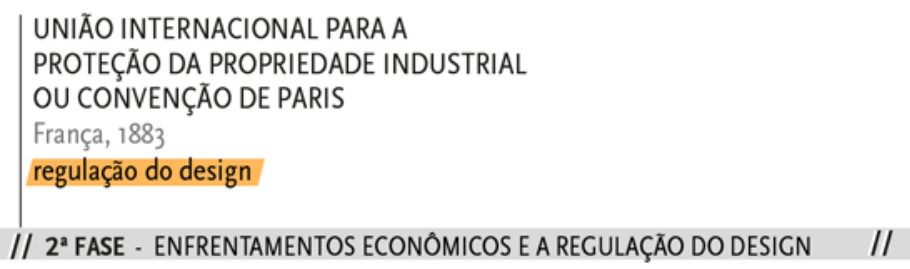

Figura 3 - Marcos históricos da 2ª fase da linha do tempo das políticas de design.

Fonte: Elaborado pelo autor.

\subsection{Terceira Fase - O Despertar do Setor Profissional do Design e a Fundação das Primeiras Escolas de Design}

O final do Século XIX e início do Século XX assistiram o despertar do setor profissional do design. Duas importantes instituições foram fundadas na Europa com o objetivo de incentivar a formação de habilidades em artesanato e design para fortalecer a indústria nacional: a Swedish Society for Crafts and Design (Sociedade Sueca de Artesanato e Design) na Suécia, em 1845; e a Finnish Society of Crafts and Design (Sociedade de Artesanato e Design da Finlândia) na Finlândia, em 1875. As associações desenvolveram atividades de ensino de habilidades manuais, atividades promocionais como exposições, publicações e eventos (STENROS, 1999; SVENSK FORM, 2013; FORUM FINLAND, 2013).

Em 1907, foi fundada a Deutsche Werkbund (Liga de Ofícios Alemã), em Munique. Era uma associação de artistas, artesãos, industriais e publicitários. Seguindo esta proposta, foram fundadas outras associações profissionais na Europa: Áustria (1910), Suécia (1910) e Suíça (1913) (BÜRDEK, 2010).

Ainda em 1913, o título de "designer industrial" foi registrado no Escritório de Patentes dos Estados Unidos como sinônimo para a "arte na indústria". Nessa mesma época, foi fundada a American Union of Decorative Artists and Craftsmen (União Americana dos Artistas Decorativos e Artesãos) (GANTZ, 2015) e pouco tempo depois, em 1915, surgiu no Reino Unido a Design and Industries Association (Associação do Design e da Indústria do Reino Unido) (WOODHAM, 1997; BÜRDEK, 2010).

É interessante perceber que nesta terceira fase, em paralelo ao surgimento de instituições nacionais e internacionais de regulação da profissão de design, está o início do ensino formal de design - ambos frutos de enfrentamentos econômicos.

Segundo Rafael Cardoso (2012), desde a primeira metade do Século XIX, os industriais ingleses da cidade de Coventry pediam ao governo que os protegesse contra a concorrência desleal estrangeira. Com isso, além da movimentação para a criação de tratados internacionais sobre propriedade industrial, eles receberam o 
primeiro sistema público de escolas de design do mundo em 1843 com a Coventry College of Design (Faculdade de Design de Coventry).

Outras duas escolas precursoras no ensino acadêmico do design foram a Bauhaus (1919) a Escola de Ulm (1953), respectivamente. As duas instituições foram fundadas na Alemanha no Século XX e tornaram-se responsáveis por disseminar políticas de ensino do design no mundo inteiro (BÜRDEK, 2010).

O plano pedagógico da Escola de Ulm tinha o objetivo de formar designers pensantes e não simplesmente executores de tarefas. A noção de um design cosmético e descartável era fortemente combatida na instituição e o aluno de design era impulsionado a refletir não apenas sobre o design, mas sobre ciências sociais, ciências cognitivas, cultura, tecnologia e política (CARDOSO, 2012).

Os avanços tecnológicos e a globalização provocaram mudanças profundas sobre as economias no final do Século XX. As nações competiam agressivamente, experimentando estratégias de competitividade na disputa por espaços no mercado internacional. Neste cenário, o ensino design se posicionou como uma poderosa ferramenta para auxiliar as economias, uma vez que habilitava a indústria a explorar o conhecimento para a criação de riqueza nos mais diversos setores de mercado.

Na Figura 4, estão indicados os principais marcos históricos desta terceira fase.

\begin{tabular}{|c|c|c|c|c|c|}
\hline $\begin{array}{l}\text { COVENTRY } \\
\text { COLLEGE } \\
\text { OF DESIGN } \\
\text { Inglaterra, } 1843 \\
\text { educação de design }\end{array}$ & $\begin{array}{l}\text { SOCIEDADE } \\
\text { SUECA DE } \\
\text { ARTESANATO } \\
\text { E DESIGN } \\
\text { Suécia, } 1845 \\
\text { associação } \\
\text { profissional }\end{array}$ & $\begin{array}{l}\text { ASSOCIAÇÕES } \\
\text { PROFISSIONAIS } \\
\text { DE DESIGN } \\
\text { Finlândia, } 1875 \\
\text { Alemanha, } 1907 \\
\text { Áustria, } 1910 \\
\text { associação } \\
\text { profissional }\end{array}$ & \begin{tabular}{|l} 
UNIÃO \\
AMERICANA \\
DOS ARTISTAS \\
DECORATIVOS \\
E ARTESÃOS \\
EUA, 1913 \\
associação \\
profissional
\end{tabular} & \begin{tabular}{|l} 
ASSOCIAÇÃO \\
DO DESIGN E \\
DA INDÚSTRIA \\
DO REINO \\
UNIDO \\
Reino Unido, 1915 \\
associação \\
profissional
\end{tabular} & $\begin{array}{l}\text { BAUHAUS } \\
\text { Alemanha, } 1819 \\
\text { educação de design } \\
\text { ESCOLA DE ULM } \\
\text { Alemanha, } 1953 \\
\text { educação de design }\end{array}$ \\
\hline
\end{tabular}

Figura 4 - Marcos históricos da 3a fase da linha do tempo das políticas de design. Fonte: Elaborado pelo autor.

\subsection{Quarta Fase - O Suporte de Design na Reconstrução das Economias no Pós-Guerra} Por volta da segunda metade do Século XX, com o término da Segunda Guerra Mundial, despontaram-se em países Europeus, então, programas governamentais como o UK Design Council no Reino Unido em 1944; o Rat für Formgebung na Alemanha em 1953; o Norwegian Design Council na Noruega em 1963. Reconhecendo a importância do design, os governos destes países elaboraram programas de suporte de design às empresas no intuito de reconstruir as economias nacionais fragilizadas pela guerra (RAULIK-MURPHY, 2010; RAULIK-MURPHY, CAWOOD, 2010).

As pequenas e médias empresas são mais vulneráveis às pressões do mercado competitivo porque, normalmente, sua experiência em design é limitada e faltam-lhe recursos para investimento em design. Por esta razão, os governos perceberam nesta quarta fase, período do pós-guerra, a necessidade de oferecer suporte de design para a sobrevivência dessas empresas. A partir disso, o design passa a ser reconhecido como um componente estratégico para os negócios.

Os marcos históricos desta quarta fase podem ser visualizados na Figura 5. 


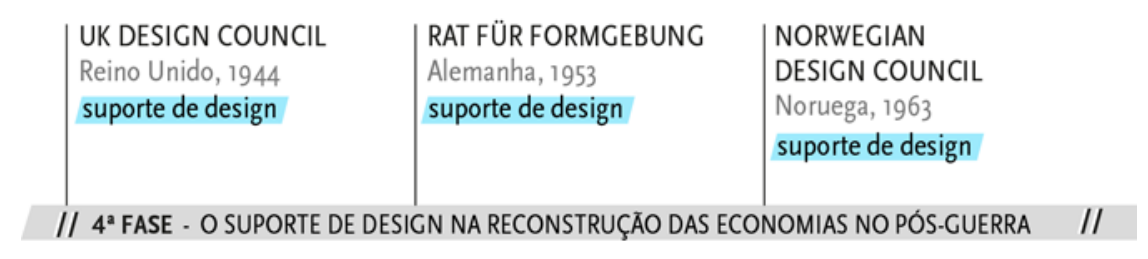

Figura 5 - Marcos históricos da 4ạ fase da linha do tempo das políticas de design.

Fonte: Elaborado pelo autor.

\subsection{Quinta Fase - Programas de Design Amplos na Europa x Promoção do Design para os Países em Desenvolvimento}

Alguns anos depois, por volta do final do Século XX e início do Século XXI, a política de design ganhou fôlego e respaldo para programas mais amplos e sistêmicos de suporte de design. Na Europa, surgiram programas estratégicos de destaque como o Design 2005! na Finlândia em 2000 e o Design Denmark iniciado em 2007 na Dinamarca (RAULIK-MURPHY, 2010; RAULIK-MURPHY, CAWOOD, 2010).

A política de design da Finlândia (2000-2005), consolidada no documento Design 2005! em junho de 2000, teve como objetivos: melhorar a qualidade do design nacional; promover o design como ferramenta competitiva para as empresas; aumentar os índices de empregabilidade do setor profissional de design; melhorar a qualidade de vida dos cidadãos; e construir identidade na cultura nacional. O projeto foi administrado pelo Ministério do Comércio e da Indústria da Finlândia e contava com o suporte do Ministério de Educação, do Ministério da Economia, de Universidades, do Conselho Nacional de Design e Artesanato e de outras instituições (RAULIK-MUPRHY, WHICHER, 2009; Design 2005!, 2000).

Desde 1997, que o governo da Dinamarca, por meio do Ministério Nacional de Negócios e Crescimento fortalece o setor de design nacional através de programas de promoção e suporte. Em 2007, foi lançado o Design Denmark, política que reuniu programas com três objetivos: assessorar as empresas dinamarquesas sobre o uso do design; aproximar o ensino de design do mercado no país; e promover o design dinamarquês internacionalmente (SCHERFIG, BRUNANDER, MELANDER, 2010; PEDERSEN, MELANDER, 2013).

Nesse mesmo período, os governos de países em desenvolvimento do Leste Europeu, Ásia e América do Sul estiveram comprometidos com um desafio diferente: mudar a percepção nacional e internacional sobre a qualidade dos seus produtos. Assim, foram lançados diferentes programas de promoção de design com o objetivo de substituir a noção de "cópia-barata" por uma interpretação que reflete excelência em design, inovação e tecnologia. É possível mencionar o nascimento de políticas de design consistentes com este objetivo em países como Estônia, Hungria, Japão, Coréia do Sul e Brasil (BLAICH, BLAICH, 1993; CHO, 2004; RAULIK-MURPHY, 2010).

Na Estônia, destacaram-se neste período duas ações: o Design Night Festival, festival de organizado pela Estonian Association of Designers (Associação de Designers da Estônia) que reúne exposições, feiras e premiações; e o Design Year, programa que promoveu ao longo do ano de 2007 uma série de palestras, workshops e outras atividades visando promover o design no país. Os programas não tiveram continuidade por falta de suporte público (SIPELGAS; TAMM, 2012).

A política de design da Hungria é organizada pela agência nacional de promoção do design Hungarian Design Council (Conselho de Design Húngaro) e visava 
sensibilizar a indústria sobre os benefícios do design. Os principais projetos são o Hungarian Design Award (Premiação de Design da Hungria) e o Moholy-Nagy László, premiação nacional para jovens designers (VÁRHELYI, 2007).

No Japão, destacaram-se neste período duas ações: em 1957, é lançada a premiação G-Mark Award, premiação japonesa do "bom design"; e em 1969, é fundada a Japan Industrial Design Promotion Organisation (Organização Nacional de Promoção do Design Industrial Japonês) (AHN; SONG, 2010).

A política de design da Coréia do Sul está integrada à sua política industrial. Os programas de design são formulados pela Design \& Brand Policy Division (Secretaria de Design \& Marca) e implementados pelo Korean Institute of Design Promotion (Instituto de Promoção do Design da Coréia do Sul), também administrado pelo governo (AHN, SONG, 2010; KIM, 2006).

No Brasil, houve em 1995 o lançamento do Programa Brasileiro do Design (PBD), cujo objetivo era promover o design brasileiro. Além de organizar a agenda de design no Brasil, o PBD buscou motivar e engajar os empresários a inserir o design no sistema produtivo e, assim, formar nos produtos nacionais uma identidade competitiva no mercado internacional (BRASIL, 1995; PBD, 2002).

O Programa Brasileiro do Design foi responsável por promover a marca Brasil no mercado externo e, entre outras ações, a financiar a participação dos designers brasileiro em premiações internacionais (Design Excellence Brazil), iniciando um processo de reconhecimento mundial para o design brasileiro (PBD, 2002; 2006; 2012).

$\mathrm{Na}$ Figura 6, apresentada a seguir, estão indicados os principais marcos históricos desta quinta fase da linha do tempo das políticas de design.

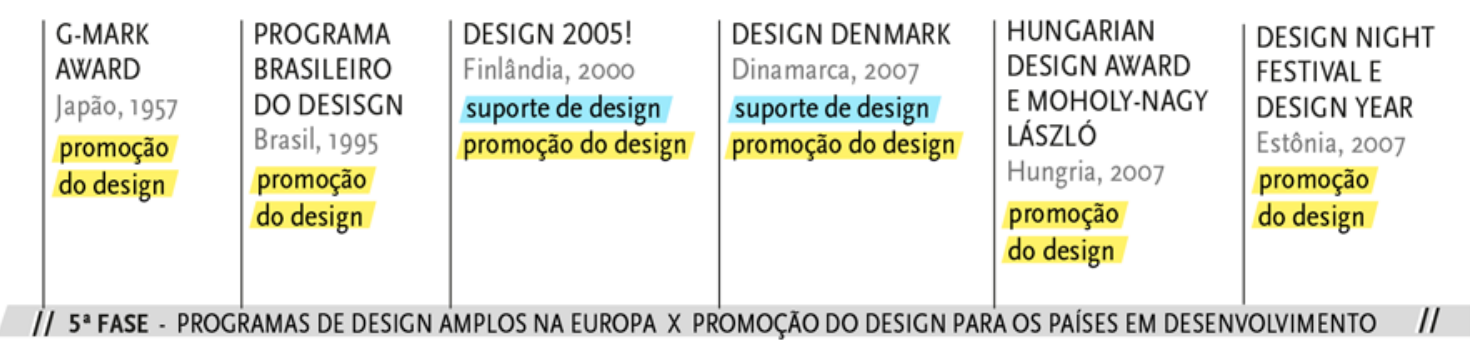

Figura 6 - Marcos históricos da 4ạ fase da linha do tempo das políticas de design. Fonte: Elaborado pelo autor.

\subsection{Sexta Fase - Políticas de Design Internacionais Integradas}

Em 2009, surgiram os primeiros sinais de que a políticas de design poderia atingir um nível mais amplo e internacional. Em uma reunião do Conselho de Competitividade da União Europeia (UE), com a aprovação do documento intitulado Towards a competitive, innovative and eco-efficient Europe - a contribution by the Competitiveness Council to the post-2010 Lisbon agenda (Rumo a uma Europa competitiva, inovadora e ecoeficiente - uma contribuição do Conselho de Competitividade à agenda de Lisboa pós-2010), foi recomendado que o Plano Europeu de Inovação incluísse o design como estratégia de desenvolvimento (RAULIK-MURPHY; MURPHY; WHICHER, 2015):

No que diz respeito ao design, que é um importante motor na inovação voltada para o usuário, o Conselho convida a Comissão e os Estados-membros a darem 
especial atenção ao design, considerando seu efeito influenciador sobre o desempenho da inovação, tendo em conta aspectos de sustentabilidade econômica, social e ambiental, e destaca a necessidade de criação de plataformas para o intercâmbio de conhecimento, experiências e melhores práticas sobre questões de design com uma vantagem competitiva para as empresas europeias (EUROPEAN COMISSION, 2010, p. 4).

Esse endosso realizado pelo Conselho da UE culminou na inclusão oficial do design em uma política de inovação da Comissão Europeia chamada Innovation Union, publicada em outubro de 2010 (RAULIK-MURPHY; MURPHY; WHICHER, 2015).

A fim de implementar o compromisso com o design firmado pela Innovation Union, foi organizado em maio de 2011 o European Design Leadership Board (EDLB) (Conselho Europeu de Liderança em Design). Além de lidar com questões como financiamento, mudanças políticas nos estados-membros da UE, gestão de pessoas e diferenças culturais, o Conselho foi encarregado de realizar ações a fim de integrar o design à política de inovação na Europa (RAULIK-MURPHY; MURPHY; WHICHER, 2015).

Dois meses após a sua formação, o EDLB lançou um convite à apresentação de propostas que tivessem o objetivo de melhorar a circulação de experiências sobre políticas de design e inovação. Seis propostas ${ }^{1}$ foram premiadas com um orçamento total de 5,3 milhões de euros (RAULIK-MURPHY; MURPHY; WHICHER, 2015).

Pesquisadores (WHICHER, CAWOOD, SWIATEK, 2015; WHICHER, RAULIKMURPHY, CAWOOD, 2011) afirmam que o reconhecimento do design como uma força de inovação por parte da Comissão Europeia tem influenciado outros atores políticos do continente, haja vista que, em 2015, quinze dos vinte e oito países membros da UE incluíram o design em suas políticas nacionais.

Além desse processo de consolidação internacional, a política de design tem tangenciado outros domínios políticos que excedem questões econômicas. Nesta sexta fase histórica das políticas de design, duas mudanças principais podem ser observadas.

Em primeiro lugar, identifica-se um movimento das políticas de design em direção à inovação social, afastando-se, dessa maneira, de uma concentração na competitividade econômica. Este fato alarga o escopo de atuação das políticas de design (RAULIK-MURPHY; CAWOOD; LEWIS, 2010).

Segundo Hugo Thénint (2008), a execução de uma política de design é entendida na Europa como vital para responder os anseios da sociedade e garantir um impacto positivo na qualidade de vida das pessoas. Com essa compreensão, países europeus têm inserido o design no setor público, a fim de remodelar os seus serviços.

\footnotetext{
${ }^{1}$ As seis propostas premiadas pelo Conselho Europeu de Liderança em Design foram as seguintes: 1 ) Casa Europeia da Gestão do Design (EHDM): construir capacidade de gestão de design no setor público; 2) Integração do "Design for All" ao "Living Lab": aproximar as comunidades de design e de living labs na Europa; 3) Plataforma SEE (Sharing Experience Europe): envolver-se com os governos nacionais e regionais e integrar o design às políticas e programas; 4) €Design - Medindo o Valor do Design: identificar e estabelecer diretrizes para medir o design como um fator econômico de produção e seu impacto sobre o PIB de países e regiões; 5) REDI - apoio regional a empresários e designers para inovar: estimular a inovação orientada pelo design e promover ecossistemas de inovação territorial em contato direto com pequenas e médias empresas; 6) DeEP - Design em Políticas Europeias: desenvolver indicadores e uma ferramenta web para avaliar políticas de inovação em design (RAULIK-MURPHY; MURPHY; WHICHER, 2015).
} 
Projetos de design desenvolvidos para o serviço público de países como o Reino Unido, Dinamarca e País de Gales têm demonstrado resultados significantes como redução abrupta de custos na prestação de serviços, aumento da eficiência dos servidores públicos em suas atividades e, o mais importante, os cidadãos estão mais seguros, informados, empoderados e satisfeitos. Em outras palavras, o design tem demonstrado sua habilidade em melhorar as experiências da sociedade com o serviço público (SEE, 2013).

Em segundo lugar, coloca-se a compreensão das políticas de design a partir de uma abordagem mais holística e sistêmica, fazendo com que os programas de design estejam integrados (RAULIK-MURPHY; CAWOOD; LEWIS, 2010).

O escopo das políticas de design apresentado nas primeiras fases da revisão histórica ora concentrado na promoção do design no sentido de criar uma cultura de design, ora concentrado no suporte de design para a sobrevivência de pequenas e médias empresa de maneira ficou estreito para as perspectivas exploradas nas políticas públicas mais recentes. Esse conceito sistêmico da política de design compreende a articulação de múltiplos elementos que precisam ser assegurados para que o design possa prosperar, trazendo benefícios econômicos e sociais.

Os acontecimentos históricos narrados neste tópico podem ser visualizados esquematicamente na Figura 7, apresentada a seguir.

\begin{tabular}{|c|c|c|}
\hline $\begin{array}{l}\text { REUNIÃO DO CONSELHO } \\
\text { DE COMPETITIVIDADE } \\
\text { DA UNIÃO EUROPEIA } \\
\text { União Européia, } 2009 \\
\text { políticas de design integradas }\end{array}$ & $\begin{array}{l}\text { INNOVATION UNION } \\
\text { União Europeia, } 2010 \\
\text { políticas de design integradas }\end{array}$ & $\begin{array}{l}\text { CONSELHO EUROPEU DE } \\
\text { LIDERANÇA EM DESICN } \\
\text { União Europeia, } 2011 \\
\text { políticas de design integradas }\end{array}$ \\
\hline
\end{tabular}

Figura 7 - Marcos históricos da 6ạ fase da linha do tempo das políticas de design. Fonte: Elaborado pelo autor.

\section{CONSIDERAÇÕES FINAIS}

O estudo apresentou uma linha do tempo das políticas de design desde o final do Século XVIII com o surgimento das Grandes Exposições até o atual Século XXI com as recentes políticas de design internacionais implantadas em países da União Européia. A estrutura proposta de seis fases tem um caráter didático e procura observar as similaridades entre os programas e políticas de design que surgem nos países a partir dos seus contextos históricos.

É importante reforçar a armadilha que existe em periodizações dessa natureza, que apesar de bem fundamentadas, tendem a esconder as distinções e especificidades dos programas e políticas de design nos diferentes países. No entanto, o autor considera este trabalho panorâmico como um produto teórico facilitador para futuras análises comparativas ou mesmo verticais sobre a temática.

As evidências apresentadas mostraram que os acontecimentos econômicos, políticos e sociais têm uma influência fundamental sobre a configuração das políticas de design. Assim, a elaboração de programas e políticas de design deve considerar o contexto nacional, de modo que este apoie o seu desenvolvimento e não comprometa a sua implantação. 


\section{REFERÊNCIAS}

AHN, Sang-Gyeun; SONG, Jeong-Man. Evaluating the Effectiveness of Asian Design Policies. Design Management Review. v. 21, n. 4, 2010. p. 78-86.

BLAICH, Robert; BLAICH, Janet. Made in Taiwan: Designing a New Image. Design Management Review. v. 4, n. 3, 1993. p. 36-40.

BRASIL. Decreto no 95. 9 de novembro de 1995. Disponível em: http://presrepublica. jusbrasil.com.br/legislacao/122250/decreto-95. Acesso em 10 out. 2015.

BÜRDEK, Bernhard. Design: História, Teoria e Prática do Design de Produtos. São Paulo: Blucher, 2010.

CARDOSO, Rafael. Design para um Mundo Complexo. São Paulo: Cosac Naify, 2012.

CHANDLER, Arthur. L'Exposition Publique des Produits de I'Industrie Française. World's Fair Bulletin. v. 10, n. 1, 1990. Disponível em: http://www.arthurchandler.com/1798exposition/. Acesso em 1 jul. 2015.

CHO, Dong-Sung. Design, Economic Development and National Policy: Lessons from Korea. Design Management Review. v. 15, n. 4, 2004, p. 10-20.

Design 2005! Helsinki: Arts Council of Finland and Finnish Ministry of Education, 2000.

EUROPEAN COMISSION. Europe 2020: A European Strategy for Smart, Sustainable and Inclusive Growth. European Commission Communication. Brussels, 2010. Disponível em: http://ec.europa.eu/eu2020/pdf/COMPLET\%20EN\%20BARROSO\%20\%20\%20007 \%20-\%20Europe\%202020\%20-\%20EN\%20version.pdf. Acesso em 20 nov. 2015.

FORUM FINLAND. History. 2013. Disponível em: http://www.designforum.fi/design_ forum_finland_en/history. Acesso em 20 out. 2015.

GANTZ, Caroll. History of IDSA: IDSA and Its Predecessors. 2015. Disponível em: http://www.idsa.org/history-idsa. Acesso em 20 out. 2015.

HOBHOUSE, Hermione. The Crystal Palace and the Great Exhibition: Science, Art and Productive Industry: A History of the Royal Commission for the Exhibition of 1851. London: Bloomsbury Academic, 2004.

HUGHES, Philip. Exhibition design. London: Laurence King, 2010.

JUNGMANN, Diana de Mello. Inovação e Propriedade Intelectual: Guia para o Docente. Brasília: SENAI, 2010.

KIM, Taewan. South Korea. Interview. SEEdesign Bulletin. Cardiff: National Centre for Product Design \& Development Research (PDR). n. 3, setembro de 2006. p. 11-12.

LAKE-HAMMOND, Alice. WAITE, Noel. Exhibition Design: Bridging the Knowledge Gap. The Design Journal. v. 13, n. 1, 2010. p. 77-98.

MACLEOD, Christine. Inventing the Industrial Revolution: The English Patent System. Cambridge, Massachusetts: Cambridge University Press, 2002.

PATROCINIO, Gabriel Henrique Torres do. The impact of European design policies and their implications on the development of a framework to support future Brazilian design policies. Tese (doutorado). Bedfordshire: Cranfield University, 2013. 
PBD. Caminhos do Design Brasileiro: Estratégias para Agregar Valor ao Produto Nacional. Brasília: Ministério do Desenvolvimento, Indústria e Comércio, 2002.

PBD. Relatório de Consolidação e Sistematização. Brasília: Ministério do Desenvolvimento, Indústria e Comércio. Encontro de Planejamento Participativo do Programa Brasileiro de Design, 2006.

PBD. Programa Brasileiro do Design e Desenvolvimento Sustentável para a Indústria: 2001-2012: Sumário de Ações. Brasília: Ministério do Desenvolvimento, Indústria e Comércio, 2012.

PEDERSEN, Rasmus; MELANDER, Christina. Denmark. Design Policy and Promotion Map. SEE Bulletin. Cardiff: National Centre for Product Design \& Development Research (PDR). n. 9, junho de 2013. p. 8.

RANJAN, M. P. India. Interview. SEEdesign Bulletin. Cardiff: National Centre for Product Design \& Development Research (PDR). n. 2, março de 2006. p. 8.

RAULIK-MURPHY, Gisele. A Comparative Analysis of Strategies for Design Promotion in Different National Contexts. Tese (doutorado). Cardiff: The University of Wales, 2010.

RAULIK-MURPHY, Gisele; CAWOOD, Gavin. Historical Review of the Paradigm Shift in Design Policies. Proceedings of the Cumulus Shanghai Conference 2010. Shanghai, China: Cumulus Shanghai Conference, 2010.

RAULIK-MURPHY, Gisele; CAWOOD, Gavin; LEWIS, Alan. Design Policy: An Introduction to What Matters. Design Management Review. v. 21, n. 4, 2010. p. 52-59.

RAULIK-MURPHY, Gisele; MURPHY, Darragh; WHICHER, Anna. Uma mudança de paradigm nas políticas: integrando o design à agenda europeia de inovação. In PATROCÍNIO, Gabriel; NUNES, José Mauro. Design e Desenvolvimento: 40 Anos Depois. São Paulo: Blucher, 2015

RAULIK-MUPRHY, Gisele; WHICHER, Anna. Design 2005!. Case Study. SEE Bulletin. Cardiff: National Centre for Product Design \& Development Research (PDR). n. 1, agosto de 2009. p. 14.

SAYER, Derek (2004). The Unbearable Lightness of Building - A Cautionary Tale. Grey Room. MIT Press. v. 16 (Summer). p. 6-35.

SCHERFIG, Christian; BRUNANDER, Merete; MELANDER, Christina. From the World's First Design Policy to the World's Best Design Policy. Design Management Review. v. 21, n. 4, 2010. p. 6-14.

SEE. Design for Public Good. Cardiff: National Centre for Product Design \& Development Research (PDR), 2013. Disponível em: http://www.seeplatform.eu/docs. Acesso em 20 out. 2015.

SIPELGAS, Kristiina; TAMM, Diana Tamm. Estonia's Design Action Plan 2012-2013. Policy in Practice. SEE Bulletin. Cardiff: National Centre for Product Design \& Development Research (PDR). n. 8, maio de 2012. p. 6-7.

STENROS, Anne. Visions of Modern Finnish Design. Keuruu: Otava Book Printing, 1999. 
SVENSK FORM. Svensk Form's History, 2013. Disponível em: http://svenskform. se/en/about-svensk-form/history/. Acesso em 20 out. 2015.

THÉNINT, Hugo. Design as a tool for innovation. Innovation Policy Workshop Report. Global Review of Innovation Intelligence and Policy Studies. Marseille: PRO INNO Europe project, 2008.

VÁRHELYI, Judit. Hungary. Interview. SEEdesign Bulletin. Cardiff: National Centre for Product Design \& Development Research (PDR). n. 4, março de 2007. p. 5.

WHICHER, Anna; CAWOOD, Gavin; SWIATEK, Piotr. SEE Policy Monitor 2015. Cardiff: National Centre for Product Design \& Development Research (PDR), 2015.

WHICHER, Anna; RAULIK-MURPHY, Gisele; CAWOOD, Gavin. Evaluating Design: Understanding the Return on Investment. Design Management Review. v. 22, n. 2, 2011. p. 44-52.

WOODHAM, Jonathan. Twentieth-Century Design. Nova York: Oxford University Press, 1997. 